\title{
Centrosome abnormalities in giant cell tumour of bone: possible association with chromosomal instability
}

\author{
Linda Moskovszky ${ }^{1}$, Katalin Dezsö ${ }^{1}$, Nick Athanasou ${ }^{2}$, Miklós Szendröi ${ }^{3}$, László Kopper ${ }^{1}$, \\ Karolina Kliskey ${ }^{2}$, Piero Picci ${ }^{4}$ and Zoltán Sápi ${ }^{1}$ \\ ${ }^{1} 1$ st Department of Pathology and Experimental Cancer Research, Semmelweis University, Budapest, \\ Hungary; ${ }^{2}$ Department of Pathology, Nuffield Orthopaedic Centre, Oxford, UK; ${ }^{3}$ Semmelweis University \\ Orthopaedic Clinic, Budapest, Hungary and ${ }^{4}$ Istituti Ortopedici Rizzoli, Laboratory of Oncologic Research, \\ Bologna, Italy
}

\begin{abstract}
Giant cell tumour of bone, a benign but potentially aggressive neoplasm, shows an increasing rate of chromosomal aneusomy that correlates with clinical course. Mechanisms that generate chromosomal instability in giant cell tumour of bone are poorly understood. One possible cause of chromosomal instability is an error in mitotic segregation due to numeric and/or functional abnormalities of centrosomes. Centrosome alteration is a common phenomenon in many cancers and has a major role in the development of chromosomal instability in cancer cells. To gain an insight into the possible mechanism for the generation of chromosomal instability in giant cell tumour of bone, we analysed 100 cases, including 57 primary nonrecurrent, 35 recurrent and 8 malignant giant cell tumour of bone cases. $\gamma$-Tubulin immunohistochemistry was performed on tissue microarrays of 59 formalin-fixed paraffin-embedded cases, whereas pericentrin and $\gamma$-tubulin fluorescent immunocytochemistry was carried out on $\mathbf{4 1}$ frozen smears. Fluorescent in situ hybridization was performed on 23 cases of pericentrin immunostained smears, allowing the simultaneous analysis of centrosomes and chromosome aberrations. Centrosome amplification was significantly higher in recurrent and malignant giant cell tumour of bones compared with nonrecurrent tumours $(P<0.001)$. A comparison of the percentage of aneusomic cells with a normal centrosome content $(4.7 \%)$ with that of aneusomic cells with centrosome amplification (6.4\%) revealed no significant association between chromosome number alterations and centrosome aberrations $(P=0.31)$. These findings indicate that centrosome alteration and frequency of aneusomy correlate with clinical behaviour; the lack of an association between centrosome amplification and chromosome number alteration suggests that alternative causative mechanisms produce genetic instability in giant cell tumour of bone.
\end{abstract}

Modern Pathology (2010) 23, 359-366; doi:10.1038/modpathol.2009.134; published online 8 January 2010

Keywords: centrosome; chromosomal instability; aneusomy; giant cell tumour of bone; predictive factor

Giant cell tumour of bone is a primary neoplasm of bone characterized by a proliferation of mononuclear stromal cells, among which are scattered numerous osteoclast-like giant cells. Giant cell tumour of bone has a variable but unpredictable course. It can recur in up to $35 \%$ of cases and can

Correspondence: Dr Z Sápi, MD, PhD, Semmelweis University, 1st Department of Pathology and Experimental Cancer Research, Üllõi út 26, Budapest 1085, Hungary.

E-mail: zsapi@freemail.hu

Received 2 June 2009; revised 10 August 2009; accepted 11 August 2009; published online 8 January 2010 produce metastatic lesions in up to $3 \%$ of cases. $^{1}$ The mixed mononuclear cell population in giant cell tumour of bone includes both reactive CD68positive macrophages and proliferating stromal cells. $^{2,3}$ Recently, it was shown that the rate of chromosomal aneusomy in the CD68-negative stromal cell population is higher in recurrent compared with nonrecurrent giant cell tumour of bones; chromosomal aneusomy was found to be clonal in most malignant cases of giant cell tumour of bone, suggesting that chromosomal instability may be responsible for aggressive behaviour. ${ }^{2}$ Possible mechanisms that might contribute to chromosomal 
instability in giant cell tumour of bone include loss of mitotic checkpoint function, defective kinetochore function and abnormal amplification of centrosomes.

A strong association has been suggested between centrosome abnormalities and degree of aneuploidy in cancers; this is because of the high prevalence of such abnormalities in solid tumours and in leukaemias and lymphomas. ${ }^{4-7}$ The centrosome is a small cytoplasmic organelle consisting of paired centrioles and surrounding protein aggregates called pericentriolar material. The pericentriolar matrix is composed of a large series of proteins including pericentrin, $\gamma$-tubulin and cell-cycle regulatory proteins. It has a key role in cytoplasmic division and regulation of cell-cycle progression, as well as in the establishment of an interphase cytoplasmic microtubule network and bipolar mitotic spindles. ${ }^{8}$

Normal diploid somatic cells contain a single centrosome that must duplicate once before the next mitosis. Thus, at any given time point during the cell cycle, cells have either one unduplicated or two duplicated centrosomes. During mitosis, the two mature centrosomes become spindle poles at the opposite ends of the cell and direct the formation of bipolar mitotic spindles. The failure to form proper bipolar mitotic spindles because of an abnormal number or function of centrosomes results in multipolar spindles and chromosome segregation errors. Amplified centrosomes frequently form pseudo-bipolar spindles by positioning on a bipolar axis (centrosome clustering); this results in mitotic spindles that structurally resemble 'true' bipolar spindles, and can cause an uneven separation of chromosomes because of their functional inactivity. ${ }^{9-12}$

Centrosome duplication and numeric integrity are controlled by cell-cycle regulatory proteins, as well as by other factors mediating DNA-damage response and/or repair mechanisms and nucleocytoplasmic transport. Aberrant control of the number and function of centrosomes can result in centrosome amplification, leading to aberrant mitotic spindles with multiple $(>2)$ spindle poles. ${ }^{10}$ The role of centrosome alterations in causing aneusomy has not been fully investigated in giant cell tumour of bone. In this study, we analysed the association between centrosome amplification and the clinical behaviour of giant cell tumour of bone, and sought to determine the role of centrosome abnormalities in the development of chromosomal aneusomy in this tumour.

\section{Materials and methods}

\section{Tissue Samples}

A total of 100 cases of giant cell tumour of bone (57 primary nonrecurrent, 35 recurrent and 8 malignant) diagnosed histologically according to the WHO criteria $^{13}$ were analysed from the archives of the
Semmelweis University Orthopaedic Clinic $(n=87)$; the Istituti Ortopedici Rizzoli $(n=3)$; and from The Nuffield Orthopaedic Centre $(n=10)$. Among the malignant cases, two were metastasizing giant cell tumour of bone, three were primary malignant giant cell tumour (a high-grade sarcoma arose within the giant cell tumour of bone) and in three cases, a sarcoma appeared at the site of previously documented giant cell tumour of bone. Immunohistochemistry was performed on tissue microarrays containing 59 giant cell tumours of bone cases (31 primary nonrecurrent, 23 recurrent and 5 malignant); the remaining 41 cases were analysed by fluorescent immunocytochemistry (26 primary nonrecurrent, 12 recurrent and 3 malignant). In two cases of recurrence, both the first and second occurrences were analysed. The mean age at first diagnosis was 32.34 (15-71) years. The mean followup time of primary nonrecurrent tumours was 94.33 (36-336) months and for the whole study population was $104.17(12-348)$ months. The majority of tumours were sited in the knee region (59\%); distal forearm (14\%), distal tibia (6\%), proximal humerus $(5 \%)$, proximal femur $(4 \%)$, metacarpus $(4 \%)$ and pelvis $(3 \%)$ were other affected tumour sites. All benign giant cell tumour of bone cases were treated similarly by intralesional curettage, followed by local adjuvant (phenol 75\% and alcohol 96\%) and bone grafting and/or bone cement packing, whereas primary or secondary malignant tumours were resected.

All patient information was coded and clinical data were available only to physicians involved in the treatment of these patients. This study was approved by the ethics committee of Semmelweis University (approval number: 230-151/20061018EKU), and all study participants gave their informed consent.

\section{Tissue Microarray Analysis, Immunohistochemistry and Fluorescent Immunocytochemistry}

Cores of $2 \mathrm{~mm}$ diameter were collected from selected areas of formalin-fixed, paraffin-embedded tissue blocks obtained from 185 giant cell tumour of bone samples. Tissue sections of $5 \mu \mathrm{m}$ thickness were cut from the blocks and after retrieval $(10 \mathrm{~min}$ boiling in citrate buffer $\mathrm{pH}$ 9), were immunostained using a mouse monoclonal anti- $\gamma$-tubulin antibody (1:2000; clone GTU-88, Sigma, St Louis, USA). Signal conversion was achieved using the iview DAB detection kit (Ventana, Tucson, AZ, USA) on the basis of an indirect streptavidin-biotin peroxidase complex method on a Ventana automated immunostaining system (Ventana 320). All incubations were performed at $37^{\circ} \mathrm{C}$ with primary antibodies for $30 \mathrm{~min}$, thereafter with the biotinylated secondary antibody for $60 \mathrm{~min}$. The immunostained tissue microarray slides were digitalized using a highresolution Mirax Desk instrument (3D Histech-Zeiss 
Ltd, Budapest, Hungary). Analysis of the mononuclear stromal cell fraction was also performed manually using light microscopy. Of the 185 formalin-fixed paraffin-embedded cases, 59 contained sufficient giant cell tumour of bone for accurate evaluation owing to the difference in the fixation and decalcination method of samples. Samples without previous decalcination showed better immunoreactivity. Samples with a background or without detectable staining were excluded.

Fluorescent immunostaining of giant cell tumour of bone mononuclear stromal cells was performed on smears derived from frozen tissue of 41 patients using mouse monoclonal anti- $\gamma$-tubulin (1:1000; clone GTU-88, Sigma) and rabbit anti-pericentrin M1-100 (1:500; gift from professor Stephen Doxsey, University of Massachusetts Medical School Department of Cell Biology, Worcester, MA, USA) as primary antibodies, and fluorescein (FITC)-conjugated goat antimouse IgG, tetramethylrhodamine (TRITC)-conjugated goat antimouse $\operatorname{IgG}(1: 100$; Sigma), TRITC-conjugated goat antirabbit IgG and FITC-conjugated goat antirabbit IgG (1:100; Jackson Immunoresearch, Newmarket, UK) as secondary antibodies. After $10 \mathrm{~min}$ fixation in $-20^{\circ} \mathrm{C}$ methanol, smears were incubated with primary $(1 \mathrm{~h})$ and then with secondary (30 min) antibodies at room temperature. PBS wash was performed between each step and the slides were mounted with DAPI (Bioview, Tel Aviv, Israel) to visualize cell nuclei.

\section{I-FISH, FISH-Relocalization}

As chromosomes are randomly affected by aneusomy in giant cell tumour of bone mononuclear cells, and only one chromosome can be examined by I-FISH, to achieve the highest possible representation of chromosomal instability in each case, we selected those chromosomes for study that showed the highest rate of aneusomy in our previous investigation. ${ }^{2}$ Accordingly, we examined specimens for abnormalities in either chromosomes X, $3,4,6$ or 11. FISH was then performed on 23 cases of pericentrin immunostained smears, allowing the simultaneous analysis of centrosome and chromosome aberrations.

Commercially available probes were used for each hybridization. Centromeric alpha satellite probes for chromosome $\mathrm{X}, 3,4,6$ and 11 were hybridized following the manufacturer's instructions (Vysis, Abott Molecular, IL, USA). A relocalization technique was also carried out in each case to avoid underscoring due to pale immunofluorescent signals after FISH procedure. After removing the coverslip from the immunostained smears, FISH was then performed on the same slide, enabling the FISH images of cells with normal and altered centrosome content to be distinguished. A Bioview Duet Automated Scanning System (Bioview) was used to relocate the previously scanned $\gamma$-tubulin immunostained images, which were matched with the FISH images of individual cells.

\section{Evaluation}

Centrosome and chromosome centromeric signals were evaluated in 100 nonoverlapping interphase giant cell tumour of bone mononuclear cells by two observers to determine centrosome and centromere number frequencies. In addition to the classic punctate arrangement, there are several types of other aberrant centrosome patterns that have been reported in neoplastic cells, such as centrosome enlargement, string-like, V-shaped and sand-like centrosome, as well as diffuse pattern. ${ }^{14,8}$ In this study, only the punctate pattern was taken into account, as this was considered to be the optimal way of detecting centrosome aberrations on formalin-fixed paraffin-embedded or frozen tissue. Cells containing one or two centrosomes were considered negative, whereas those containing more than two centrosomes were regarded as positive (that is, showing centrosome amplification). Centrosome amplification was graded in each specimen as follows: negative $(0-2 \%$ of cells); weak $(2-10 \%$ of cells); moderate (11-20\% of cells); and strong (more than $21 \%$ of cells). ${ }^{15}$ On the basis of individual centromeric signals of the examined chromosomes, monosomy, trisomy and 5X, 6X, 7X chromosomal sets were regarded as aneusomy; cells with polysomy, that is, regular multiples of centromeric signals (for example, 4X, 8X) were not scored. As only one chromosome was examined per case, the aberrant centrosome number in a disomic cell was not taken into consideration. I-FISH evaluation only investigated the frequency of aneusomic cells with a normal centrosome content and of aneusomic cells with centrosome amplification.

For statistical analysis, Pearson's $t$-test and linear regression analysis were performed, with results considered significant at $P<0.001$.

\section{Results}

\section{Centrosome Profile and Clinical Behaviour}

Centrosome amplification was found to be present in mononuclear stromal cells derived from not only malignant but also benign cases of giant cell tumour of bone. Out of the 100 cases examined either by immunohistochemistry or fluorescent immunocytochemistry, all 57 primary nonrecurrent giant cell tumour of bones showed negative or weak centrosome amplification. Of the 35 recurrent cases, 23 proved to be moderate or strong positive, whereas every malignant case was moderate/strong positive.

The feature of centrosome clustering was examined separately from centrosome amplification. Of the $23(60.87 \%)$ I-FISH analysed cases, 14 showed centrosome clustering; this did not correlate with 


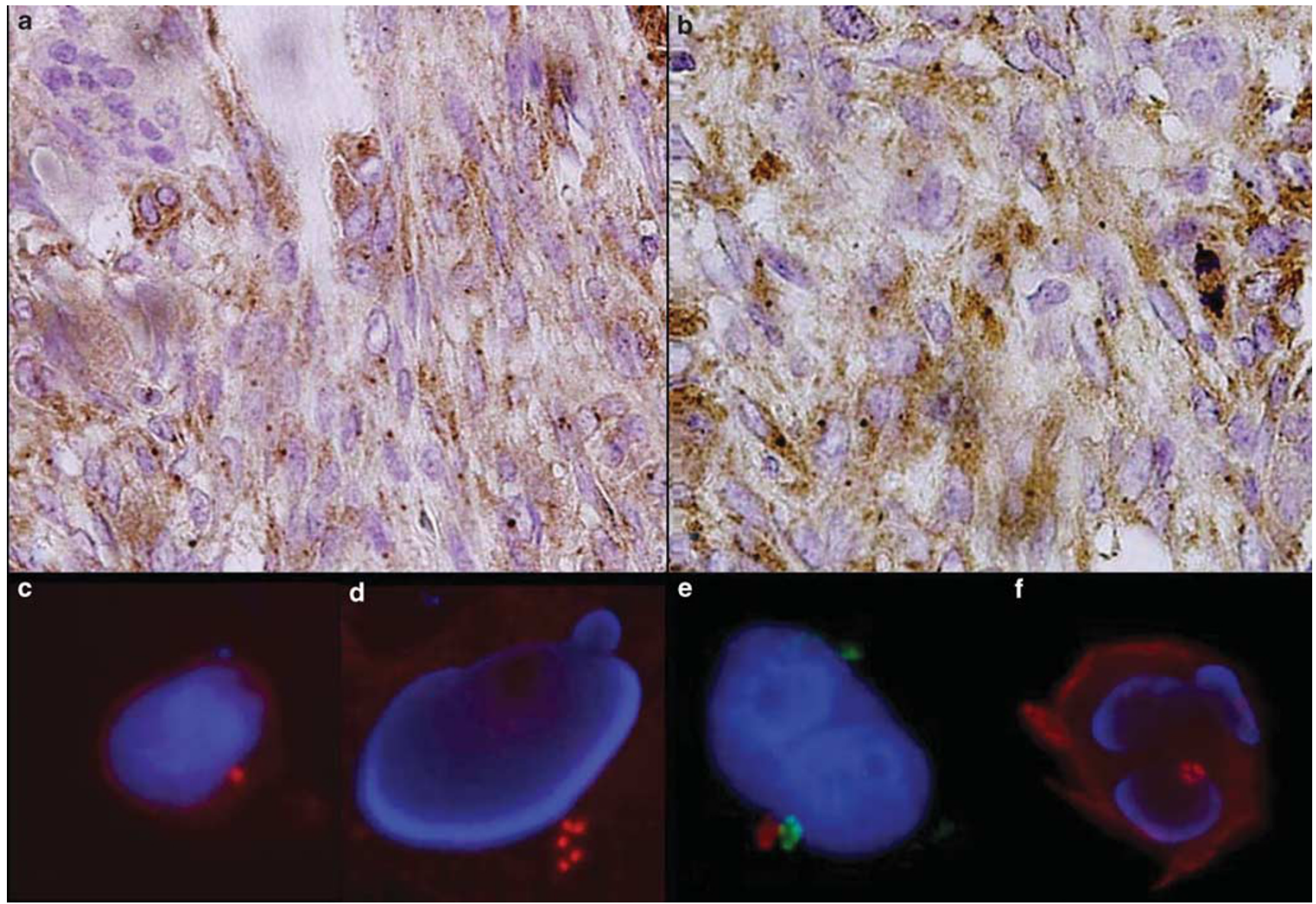

Figure 1 Centrosome profiles. $\gamma$-Tubulin expression of a primary nonrecurrent case (a, c) with a normal centrosome pattern and a recurrent case $(\mathbf{b}, \mathbf{d})$ showing centrosome amplification/enlargement. Pericentrin (red) colocalizing with $\gamma$-tubulin (green) showed a high frequency of centrosome amplification in malignant giant cell tumour of bones (e). Of the 23 (60.87\%) I-FISH analysed cases, 14 showed centrosomal clustering regardless of clinical behaviour, varying between $3-18 \%$ per case (f).

the clinical behaviour of giant cell tumour of bone and was observed in $3-18 \%$ of examined cells (Figure 1). Centrosome amplification was significantly higher in recurrent and malignant cases than in nonrecurrent tumours $(P<0.001)$ (Figure 2a). A similar correlation was found by I-FISH analysis alone, in which the rate of centrosome amplification was higher in malignant (36.5\%) compared with recurrent $(16.6 \%)$ and nonrecurrent $(5 \%)$ giant cell tumour of bone cases $(P<0.001)$ (Figure $2 b)$.

\section{Chromosome Number and Centrosome Aberrations}

A statistically significant correlation was detected between centrosome number alteration and chromosomal instability in mononuclear cells (Figure 3a). At the single cell level, analysis of the frequency of aneusomic cells with a normal centrosome content and aneusomic cells with centrosome amplification by I-FISH showed no significant association between chromosome number alterations and centrosome aberrations $(P=0.31)$ (Figure $3 \mathrm{~b}$ ). Out of the 23 I-FISH analysed cases,
$4.69 \pm 2.84 \%$ of cells showed aneusomy and a normal centrosome content, whereas $6.47 \pm 5.36 \%$ of cells showed aneusomy with an amplified centrosome number.

Primary nonrecurrent tumours could be characterized by a normal chromosome and centrosome content: the frequencies of aneusomic cells with both normal and amplified centrosomes were low, $4.33 \pm 2.13 \%$ and $2.46 \pm 1.23 \%$, respectively. In recurrent tumours, the frequency of aneusomic cells with a normal centrosome content was $3.33 \pm 2.44 \%$, whereas the frequency of those with amplified centrosomes was elevated (9.66 $\pm 2.33 \%)$. In keeping with our previous findings, the two malignant cases of giant cell tumour of bone examined in this study showed a higher percentage of aneusomy, with $11.5 \pm 3.5 \%$ of aneusomic cells with normal centrosomes and $27 \pm 4 \%$ of aneusomic cells with amplified centrosomes (Figures 3b and 4).

Although only a limited number of cases (seven primary nonrecurrent, three recurrent and one malignant) were examined, no significant difference was found between the frequency of polysomic cells with a normal centrosome content $(2.09 \pm 1.19 \%)$ 

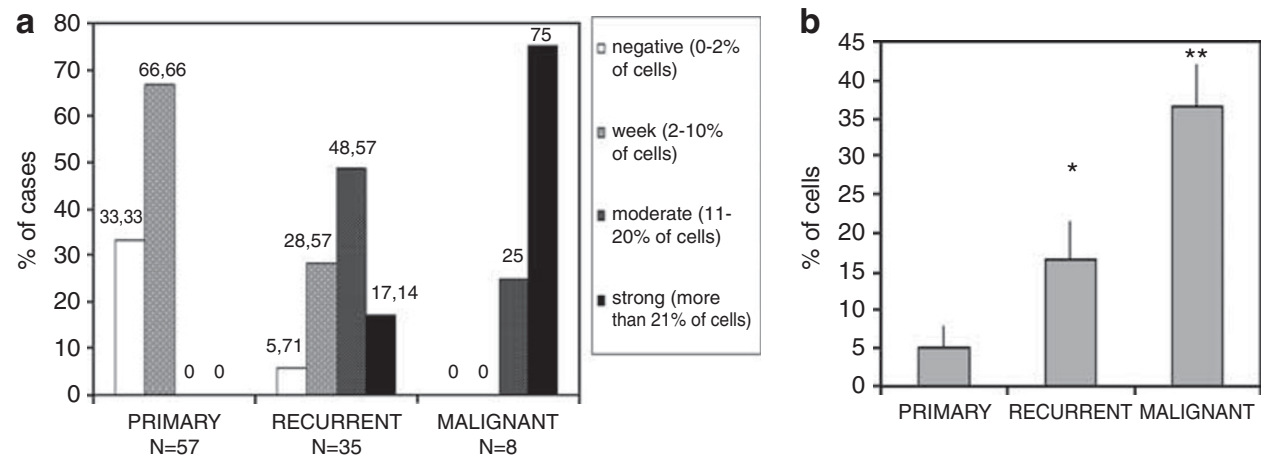

Figure 2 Correlation of centrosome alteration with clinical aggressiveness. Centrosome amplification was significantly higher in recurrent and malignant giant cell tumour of bones compared with that in nonrecurrent tumours $(P<0.001)(\mathbf{a})$. A consonant correlation was found by I-FISH analysis alone, in which the rate of centrosome amplification was higher in malignant $(36.5 \%)$ compared with recurrent $(16.6 \%)$ and nonrecurrent $(5 \%)$ cases $(P<0.001)(\mathbf{b})$.

a Scatterplot: Centrosome Number / 100 cells vs. Aneusomy Correlation: $r=, 8828$
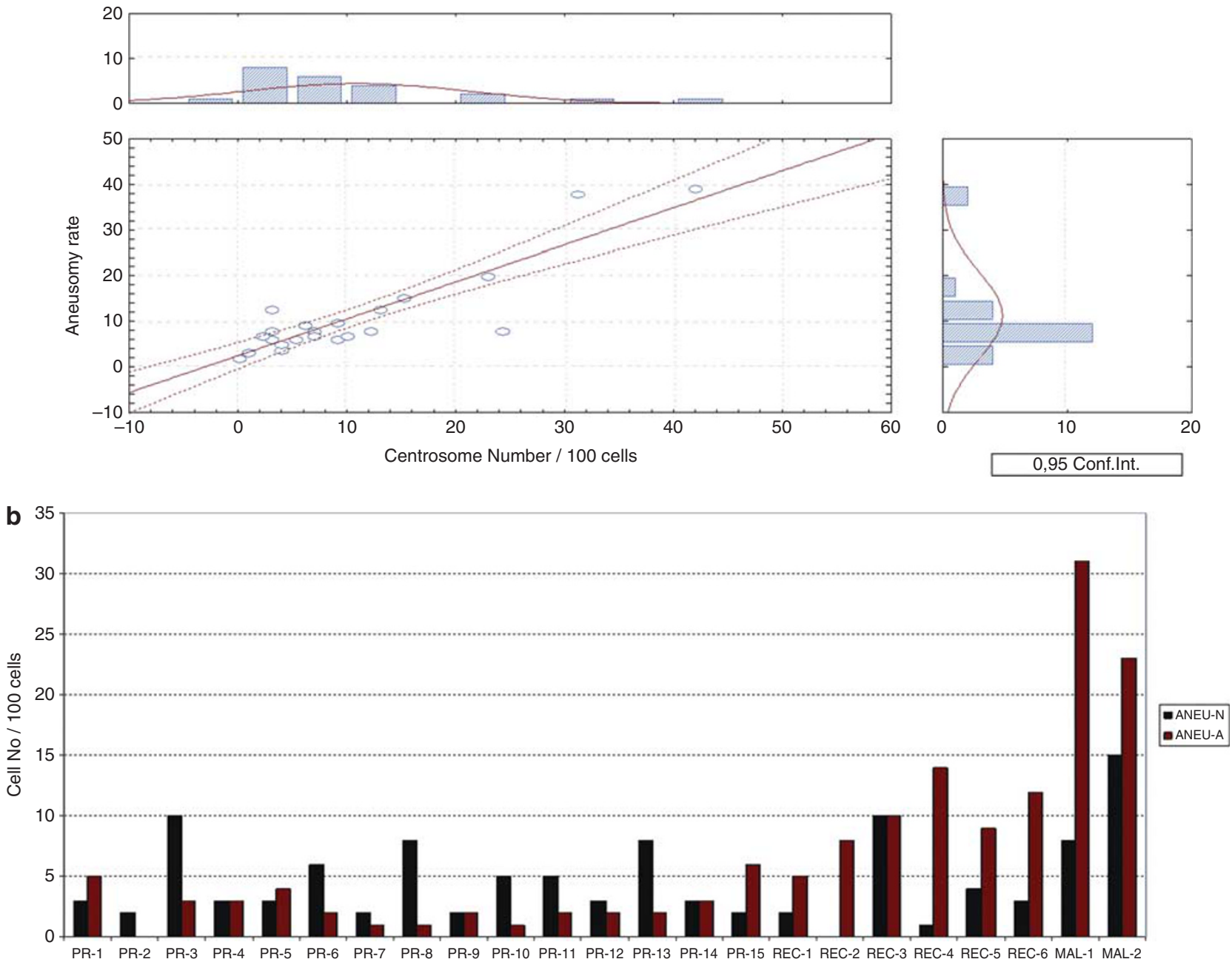

Figure 3 Chromosome number and centrosome aberrations. Although a strong correlation $(P<0.001)$ could be assumed between CIN and centrosome amplification, suggesting a possible generating role of centrosome abnormalities in the genetic instability of giant cell tumour of bone (a), analysing excusively the aneusomic cells in 23 cases, the rate of aneusomic cells with a normal centrosome content (ANEU-N) and those with centrosome amplification (ANEU-A) revealed no significant association between chromosome number alterations and centrosome aberrations (b). MAL, malignant giant cell tumour of bone, PR, primary nonrecurrent giant cell tumour, REC, benign recurrent giant cell tumour. 


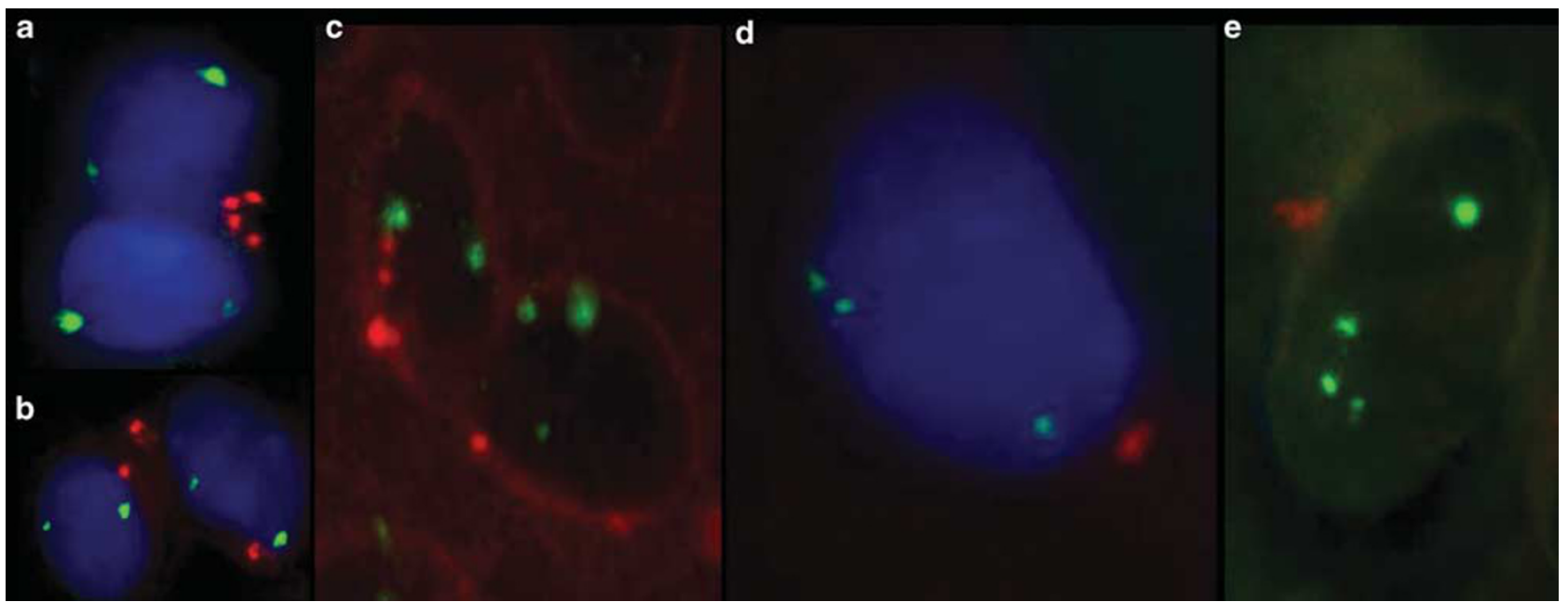

Figure 4 I-FISH images: pericentrin (red) immunostaining combined with FISH (green centromeric probe for chromosome 4). Primary nonrecurrent cases could be characterized by normal disomic FISH and centrosome pattern (b); often, centrosomal clustering between two or three cells could be observed (a). As the chromosomes are randomly affected by aneusomy in this tumour and only one chromosome was examined per case, the aberrant centrosome number in a disomic (c, cell on the left) or polysomic (e) cell was not taken into consideration. In general, no significant correlation was found between chromosome number alteration and centrosome aberration: trisomic cells with nonamplified centrosomes (c, cell on the right; d).

and that of polysomic cells with centrosome amplification $(3.63 \pm 2.62 \%)$ by I-FISH (data not shown).

\section{Discussion}

This study has examined possible mechanisms for the generation of genetic instability in giant cell tumour of bone. Finding a higher frequency of centrosome aberration in recurrent and malignant giant cell tumour of bones compared with nonrecurrent giant cell tumour of bones, we sought to determine whether centrosome amplification may have an initiating role in the generation of chromosomal instability. Our results show that centrosome amplification and aneusomy rate independently correlate with clinical outcome in giant cell tumour of bone. We have previously shown that random aneusomy is a feature of the CD68-negative mononuclear stromal cell population of giant cell tumour of bone, and that this feature correlates with biological aggressiveness, with chromosomal gain and loss turning into clonal but random genetic aberrations in malignant cases. ${ }^{2}$ In this study, we show that there is a strong correlation between chromosomal instability and centrosome amplification, suggesting a possible involvement of the latter in generating chromosomal instability in giant cell tumour of bone. However, relocalization studies and immunocytochemistry, in combination with FISH, showed no association between centrosome amplification and chromosome number alteration, indicating that alternative causative mechanisms are responsible for generating genetic instability in giant cell tumour of bone.
To date, several molecular mechanisms have been implicated in chromosomal instability, including pathways affecting telomere and centromere stability, cell-cycle regulators, chromosome segregation and centrosome duplication, separation, maturation and pairing; ${ }^{16,10}$ breakage-fusion-bridge events are also reported to be frequent in malignant tumours with nonspecific chromosome aberrations. ${ }^{17}$ Certain oncogenic and tumour-suppressor proteins could directly induce chromosomal instability in giant cell tumour of bone by disrupting the functional and numeric integrity of centrosomes. ${ }^{10}$ The tumoursuppressor gene TP53 damage results in further cell cycling of cells with centrosome defects, without cytokinesis, which can result in the selection of aneuploid cells. ${ }^{4}$ TP53 overexpression as an indicator of TP53 mutation has been correlated with lung metastasis and recurrence of giant cell tumour of bone according to some but not all observers. ${ }^{18-20}$ The cell-cycle regulator protein, CCND1, together with $C D K N 1 A$, both of which have a regulatory role in centrosome reduplication, has also been reported to be overexpressed in the giant cell component of giant cell tumour of bone. ${ }^{21-22} \mathrm{~A}$ possible role of the oncogene $M Y C C$ has also been suggested in the pathogenesis of this tumour by Gamberi et $a l,{ }^{23}$ who found that MYCC was overexpressed in both the giant cell and mononuclear cell populations of metastatic cases of giant cell tumour of bones. Overexpression of MYCC can lead to G2/M arrest and genomic instability. ${ }^{24}$ Membrane and cytoplasmic expression of CTNNB1, a member of the Wnt signalling pathway, has been observed in giant cell tumour of bone; although the failure of this signalling route (usually with the nuclear accumulation of CTNNB1) is well known to cause aneusomies and tetrasomies, ${ }^{25}$ no significant correlation has been 
observed between CTNNB1 positivity and the degree of aneusomy in giant cell tumour of bone, or between CTNNB1 expression and giant cell tumour of bone recurrence. ${ }^{2,26}$ One of the most commonly observed genetic aberrations in giant cell tumour of bone is telomeric association. Telomeric association alone, however, does not have a role in the development of genetic instability. ${ }^{27}$

The role of aberrant centrosome number in generating chromosomal instability has not previously been fully investigated at the individual cell level in borderline tumours and, to our knowledge, this is the first report examining the direct role of supernumerary centrosomes in the generation of chromosomal instability in a large series of giant cell tumour of bone, a tumour that shows a variable degree of aggressive behaviour and can rarely metastasize. There is evidence that centrosome aberrations are common in malignant mesenchymal tumours such as osteosarcoma, ${ }^{28}$ which exhibit a high rate of aneuploidy. Opinions regarding the direct role of centrosome aberrations in the generation of chromosomal instability are conflicting. Statistical correlation of centrosome number and the rate of aneusomy has shown in some studies that mitotic multipolarity caused by supernumerary centrosomes is responsible for the generation of aneusomy in epithelial neoplasms, such as breast and colorectal cancer. ${ }^{29,30}$ However, similar to our findings in this study with giant cell tumour of bone, other malignant epithelial and benign and malignant mesenchymal tumours showed no correlation between centrosome number and the frequency of aneusomy. ${ }^{31,7}$

We found that centrosome amplification was present in benign giant cell tumour of bone cases, which shows that this phenomenon is not characteristic of malignant giant cell tumour of bones. However, correlation with giant cell tumour of bone behaviour suggests that centrosome amplification may be useful in predicting the clinical behaviour of this tumour. Our finding that chromosomal instability and centrosome aberrations did not associate at the single cell level indicates that centrosome amplification alone may not be responsible for inducing mitotic abnormalities in giant cell tumour of bone. Given the clinical importance of identifying reliable markers that predict the behaviour of this tumour, especially at the first time of recurrence, a more detailed analysis to identify factors regulating centrosome function in giant cell tumour of bone is indicated.

\section{Acknowledgements}

We thank professor Stephen Doxsey (the University of Massachusetts Medical School Department of Cell Biology, Worcester, MA, USA) and professor Pavel Draber (Institute of Molecular Genetics, Academy of Sciences of the Czech Republic) for their technical advice and antibodies. This study was supported by the EuroBoNeT consortium, a KP-6 European Commission-granted Network of Excellence for studying the pathology and genetics of bone tumours (research grant G.0117.06).

\section{Disclosure/conflict of interest}

The authors declare no conflict of interest.

\section{References}

1 Szendroi M. Giant-cell tumour of bone. J Bone Joint Surg 2004;86:5-12.

2 Moskovszky L, Szuhai K, Krenacs T, et al. Genomic instability in giant cell tumor of bone. A study of 52 cases using DNA ploidy, relocalization FISH, and array-CGH analysis. Genes Chromosomes Cancer 2009; 48:468-479.

3 Joyner CJ, Quinn JM, Triffitt JT, et al. Phenotypic characterisation of mononuclear and multinucleated cells of giant cell tumour of bone. Bone Miner 1992;16:37-48.

4 Fukasawa K. Centrosome amplification, chromosome instability and cancer development. Cancer Lett 2005;230:6-19.

5 Doxsey S. The centrosome-a tiny organelle with big potential. Nat Genet 1998;20:104-106.

6 D'Assoro AB, Lingle WL, Salisbury JL. Centrosome amplification and the development of cancer. Oncogene 2002;21:6146-6153.

7 Gisselsson D, Palsson E, Yu C, et al. Mitotic instability associated with late genomic changes in bone and soft tissue tumours. Cancer Lett 2004;206:69-76.

8 Katsetos CD, Reddy G, Draberova E, et al. Altered cellular distribution and subcellular sorting of gammatubulin in diffuse astrocytic gliomas and human glioblastoma cell lines. J Neuropathol Exp Neurol 2006;65:465-477.

9 Quintyne NJ, Reing JE, Hoffelder DR, et al. Spindle multipolarity is prevented by centrosomal clustering. Science 2005;307:127-129.

10 Fukasawa K. Oncogenes and tumour suppressors take on centrosomes. Nat Rev Cancer 2007;7:911-924.

11 Doxsey S. Duplicating dangerously: linking centrosome duplication and aneuploidy. Mol Cell 2002;10:439-440.

12 Doxsey S. Re-evaluating centrosome function. Nat Rev Mol Cell Biol 2001;2:688-698.

13 Reid R, Banerjee S, Sciot R. Giant cell tumour. In: Fletcher C, Unni K, Mertens F, (eds). World Health Organization Classification of Tumours. Pathology and Genetics of Tumours of Soft Tissue and Bone. IARC: Lyon, 2002, pp 310-312.

14 Guo HQ, Gao M, Ma J. et al. Analysis of the cellular centrosome in fine-needle aspirations of the breast. Breast Cancer Res 2007;9:R48.

15 Gustafson LM, Gleich LL, Fukasawa K, et al. Centrosome hyperamplification in head and neck squamous cell carcinoma: a potential phenotypic marker of tumor aggressiveness. Laryngoscope 2000;110:1798-1801.

16 Perera S, Bapat B. Genetic instability in cancer. http:// AtlasGeneticsOncology.org/Deep/GenetInstabilityCancerID20056.html. 
17 Gisselsson D, Pettersson L, Hoglund M, et al. Chromosomal breakage-fusion-bridge events cause genetic intratumor heterogeneity. Proc Natl Acad Sci USA 2000;97:5357-5362.

18 Masui F, Ushigome S, Fujii K. Giant cell tumor of bone: an immunohistochemical comparative study. Pathol Int 1998;48:355-361.

19 Oda Y, Sakamoto A, Saito T, et al. Secondary malignant giant-cell tumour of bone: molecular abnormalities of p53 and H-ras gene correlated with malignant transformation. Histopathology 2001;39: 629-637.

20 de Souza PE, Paim JF, Carvalhais JN, et al. Immunohistochemical expression of p53, MDM2, ki-67 and PCNA in central giant cell granuloma and giant cell tumor. J Oral Pathol Med 1999;28: 54-58.

21 Kandel R, Li SQ, Bell R, et al. Cyclin D1 and p21 is elevated in the giant cells of giant cell tumors. J Orthop Res 2006;24:428-437.

22 Kauzman A, Li SQ, Bradley G, et al. Cyclin alterations in giant cell tumor of bone. Mod Pathol 2003;16: 210-218.

23 Gamberi G, Benassi MS, Bohling T, et al. Prognostic relevance of C-myc gene expression in giant-cell tumor of bone. J Orthop Res 1998;16:1-7.

24 Felsher DW, Bishop JM. Transient excess of MYC activity can elicit genomic instability and tumorigenesis. Proc Natl Acad Sci USA 1999;96:3940-3944.
25 Yang Y, Fruehauf J, Xiang S, et al. Genomic instability in precancerous lesions before inactivation of tumor suppressors p53 and APC in patients. Cell Cycle 2006;5:1443-1447.

26 Monaghan H, Bubb VJ, Sirimujalin R, et al. Adenomatous polyposis coli (APC), beta-catenin, and cadherin are expressed in human bone and cartilage. Histopathology 2001;39:611-619.

27 Forsyth RG, De Boeck G, Bekaert S, et al. Telomere biology in giant cell tumour of bone. J Pathol 2008;214:555-563.

28 Al-Romaih K, Bayani J, Vorobyova J, et al. Chromosomal instability in osteosarcoma and its association with centrosome abnormalities. Cancer Genet Cytogenet 2003;144:91-99.

29 Lingle WL, Barrett SL, Negron VC, et al. Centrosome amplification drives chromosomal instability in breast tumor development. Proc Natl Acad Sci USA 2002;99: 1978-1983.

30 Ghadimi BM, Sackett DL, Difilippantonio MJ, et al. Centrosome amplification and instability occurs exclusively in aneuploid, but not in diploid colorectal cancer cell lines, and correlates with numerical chromosomal aberrations. Genes Chromosomes Cancer 2000;27:183-190.

31 Shimomura A, Miyoshi Y, Taguchi T, et al. Association of loss of BRCA1 expression with centrosome aberration in human breast cancer. J Cancer Res Clin Oncol 2009;135:421-430. 